\title{
ISOTOPIC LABELLING OF THE MOUSE BLASTOCYST
}

\author{
I. B. WILSON AND M. S. R. SMITH* \\ Department of Zoology, University College of North Wales, \\ Bangor, Caernarvonshire
}

\section{(Received 19th January 1968)}

In the implanting blastocyst of the mouse, the first trophoblast cells to penetrate the uterine epithelium contain large basophil inclusions. It has been suggested that these inclusions originate at an earlier stage within cells of the inner mass which move into the trophoblast just after disintegration of the zona pellucida (Wilson, 1963; Potts \& Wilson, 1967). An attempt has been made to prove that these cells and their inclusions, 'primary invasive cells' (Wilson, 1963), are of embryonic origin and that they do penetrate the maternal tissues some time before general epithelial disintegration occurs.

The experimental procedure was as follows. Morulae and early blastocysts were collected at 72 to $76 \mathrm{hr}$ post coitum from hybrid stock females. Eggs were cultured at $37.5^{\circ} \mathrm{C}$ in Krebs-bicarbonate-Ringer with added glucose and bovine serum albumin (both at $0.1 \%$ ) and antibiotics. The same solution was used for all manipulations. Either $0.1 \mu \mathrm{c} / \mathrm{ml}$ of tritiated thymidine (specific activity $5 \mathrm{c} / \mathrm{m}$-mole; Radiochemical Centre, Amersham, Bucks.) or 0.15 $\mu \mathrm{c} / \mathrm{ml}$ of tritiated uridine (specific activity $3 \mathrm{c} / \mathrm{m}$-mole) was added to the medium and the eggs were cultured for $24 \mathrm{hr}$ in a small drop of this fluid (approx. $0.02 \mathrm{ml}$ ) under liquid paraffin gassed with $95 \%$ air: $5 \% \mathrm{CO}_{2}$.

The cultured eggs were washed twice and then transferred to pseudopregnant hybrid females at 76 to $80 \mathrm{hr}$ p.c. These females were killed at intervals from 24 to $42 \mathrm{hr}$ after transfer. The uteri were fixed in Clarke's fluid ( 3 parts absolute alcohol: 1 part glacial acetic acid), embedded in ester wax and sectioned at 4 or $5 \mu$.

The thymidine-labelled material was then covered with Kodak ARIO autoradiographic stripping film and exposed, in the cold, for about 8 weeks. Development was in Kodak D19B, followed by staining with Ehrlich's haematoxylin. The tritiated uridine sections were first stained with Heidenhain's haematoxylin, mounted and photographed before autoradiography. The coverslips were removed from these slides and the sections brought back to water before putting on the stripping film. After approximately 8 weeks the slides were developed in D19B but no further staining was done.

A total of twenty-seven apparently normal eggs, labelled with tritiated thymidine, were sectioned. Fifteen of these were in an early stage of attachment with the uterine epithelium still present and twelve were at egg cylinder stages with no epithelium remaining around the implantation chamber. Three specimens in which the epithelium were still present showed clear signs of

* Present address: Department of Zoology, The University, Southampton. 
activity in basal regions of the epithelium, though it was not possible to identify the structure containing the activity. In one of these three cases there was evidence of activity amongst stromal cells in two consecutive sections showing silver grain development at the same location (Pl. 1, Figs. 3 and 4), though again it was not possible to distinguish the structure of the source.

Thirty-four eggs labelled with tritiated uridine have been observed in stages from early attachment, with intact epithelium and no apparent decidual reaction, to late egg cylinder stages with trophoblastic giant cells invading the uterine stroma.

In specimens with apparently intact uterine epithelium, trophoblastic protrusions with dark staining inclusions can be seen penetrating between epithelial cells (Pl. 1, Figs. 1 and 2). Silver grains are well developed over the clear cytoplasmic areas of such trophoblast cells and over the inclusions, but the density over the latter is not as great as might be expected when considering their high RNA content (Potts \& Wilson, 1967) and assuming good incorporation of tritiated uridine into this RNA. It seems probable that our present system for culturing the eggs does not allow maximum incorporation of tritiated uridine into the RNA of the inclusions, for the following reasons. Viability of the blastocysts is impaired if more than the minute trace of radio-activity specified is present in the culture medium. Development to the blastocyst stage will certainly proceed in the presence of higher levels but numerous experiments have shown that such blastocysts degenerate shortly after transfer to recipient females. The small trace of precursor in the medium is probably taken up quite quickly by the developing blastocysts and bound into nucleoproteins in the first few hours of culture. Consequently little, if any, label will remain 'free' to be incorporated at a later stage, so unless the constituents of the inclusion are synthesized in this early period they will not acquire much radio-activity.

We are currently engaged on a series of experiments to define more precisely the period during which inclusions are formed in cells of the inner mass so that we can culture the eggs with isotope freely available at this time.

\section{EXPLANATION OF PLATE 1}

All figures are of transverse sections of the uterus. The space in the uterine lumen, between the blastocyst and epithelium, and space showing between the epithelium and its basement membrane, as in Figs. 3 and 4, is a shrinkage artefact. The scale line on the figures represent $10 \mu$.

Frg. 1. An inclusion (arrowed) is shown in a trophoblast cell protrusion which is penetrating otherwise intact epithelium. This blastocyst had been labelled with tritiated uridine and transferred to a pseudopregnant mouse which was killed $24 \mathrm{hr}$ after transfer. Fic. 2. Same section as in Fig. 3 after autoradiography. Silver grains are well developed over the trophoblast cell and its inclusion.

FrG. 3. Autoradiograph of blastocyst labelled with tritiated thymidine and fixed $24 \mathrm{hr}$ after transfer to pseudopregnant mouse. (Stained with Ehrlich's haematoxylin.) Silver grains (arrowed) have developed over stromal cells but the source could not be identified. Fig. 4. Adjacent section to that shown in Fig. 3 from same blastocyst. Silver grains have developed over the same stromal location as in Fig. 3 and also at the base of epithelial cells. 
PI ATE 1
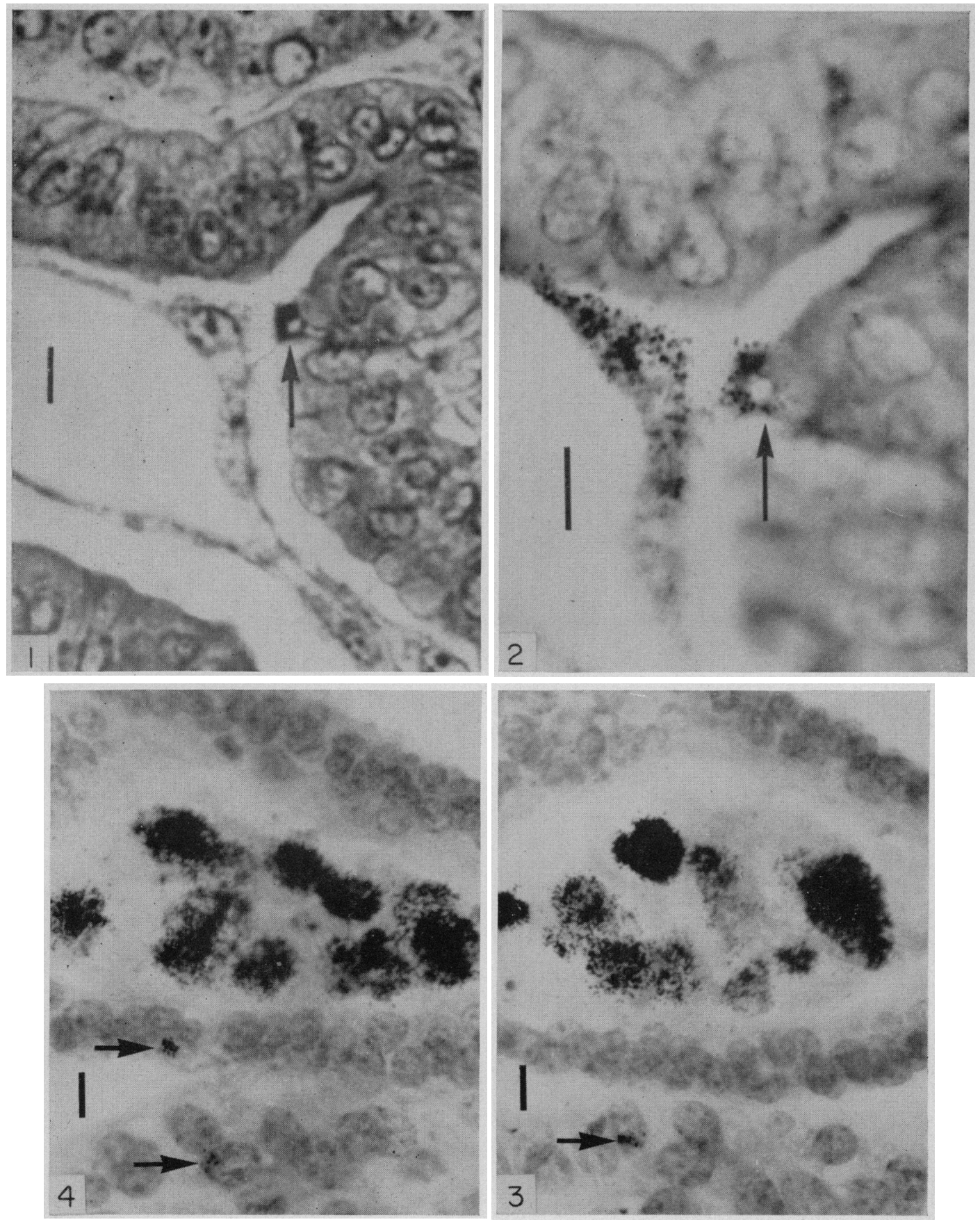

(Facing p. 306) 
We wish to express our gratitude to Professor F. W. R. Brambell for his encouragement in this work and for criticism of the manuscript. One of us (M.S.R.S.) is particularly indebted to Professor Brambell for the opportunity to work in Bangor and to The Wellcome Trust for the award of a Post-Doctoral Research Fellowship during tenure of which this work was undertaken.

\section{REFERENCES}

PotTs, D. M. \& WiLson, I. B. (1967) The preimplantation conceptus of the mouse at 90 hours post-coitum. 7. Anat. 102, 1.

WiLson, I. B. (1963) A new factor associated with the implantation of the mouse egg. F. Reprod. Fert. $5,281$. 